\title{
ARTICLE \\ LPS-binding IgG arrests actively motile Salmonella Typhimurium in gastrointestinal mucus
}

\author{
Holly A. Schroeder ${ }^{1}$, Jay Newby ${ }^{2}$, Alison Schaefer ${ }^{1}$, Babu Subramani ${ }^{1}$, Alan Tubbs ${ }^{3}$, M. Gregory Forest ${ }^{2}$, Ed Miao ${ }^{3}$ and Samuel K. Lai $^{1,4}$
}

The gastrointestinal (Gl) mucosa is coated with a continuously secreted mucus layer that serves as the first line of defense against invading enteric bacteria. We have previously shown that antigen-specific immunoglobulin $\mathrm{G}$ (IgG) can immobilize viruses in both human airway and genital mucus secretions through multiple low-affinity bonds between the array of virion-bound lgG and mucins, thereby facilitating their rapid elimination from mucosal surfaces and preventing mucosal transmission. Nevertheless, it remains unclear whether weak IgG-mucin crosslinks could reinforce the mucus barrier against the permeation of bacteria driven by active flagella beating, or in predominantly MUC2 mucus gel. Here, we performed high-resolution multiple particle tracking to capture the real-time motion of hundreds of individual fluorescent Salmonella Typhimurium in fresh, undiluted GI mucus from Rag $1^{-1-}$ mice, and analyzed the motion using a hidden Markov model framework. In contrast to control IgG, the addition of antilipopolysaccharide IgG to GI mucus markedly reduced the progressive motility of Salmonella by lowering the swim speed and retaining individual bacteria in an undirected motion state. Effective crosslinking of Salmonella to mucins was dependent on Fc $\mathrm{N}$-glycans. Our findings implicate lgG-mucin crosslinking as a broadly conserved function that reduces mucous penetration of both bacterial and viral pathogens.

Mucosal Immunology (2020) 13:814-823; https://doi.org/10.1038/s41385-020-0267-9

\section{INTRODUCTION}

Enteric pathogens, including viruses and intracellular obligate bacteria, must first penetrate the gastrointestinal mucus (GIM) layer to reach and infect the host epithelium. ${ }^{1-3}$ In the case of Salmonella, the bacteria must also come into direct contact with host cells to establish initial attachment and inject virulence effectors via the type III secretion system. ${ }^{4}$ These longstanding observations suggest that limiting mucus penetration should provide an effective way to prevent and/or treat infections. The dense network of mucin fibers is capable of sterically obstructing diffusion of particles that are too large to fit through the pores in mucus. Mucous can also form direct adhesive bonds with foreign particles to impede the movement of particles that are smaller than the mucous pore size. ${ }^{5,6}$ Bacteria have evolved a variety of mechanisms to avoid becoming immobilized in mucus, ${ }^{7}$ such as active flagellar motility ${ }^{8}$ or secretion of enzymes that degrade mucins. ${ }^{6,9}$

Antibodies are abundant in mucus, including immunoglobulin $\mathrm{G}(\mathrm{IgG}){ }^{10-13}$ Interestingly, the diffusion of $\operatorname{lgG}$ and $\operatorname{lgA}$ antibodies in mucus is only slowed $\sim 10-20 \%$ compared to in buffer; this implies that the vast majority of $\lg$ and $\lg A$ molecules are not interacting with mucins at any moment in time, and that any bond with mucins is exceptionally short-lived. ${ }^{14-16}$ Despite this seemingly negligible affinity, we recently showed that IgG can effectively immobilize individual viruses in both fresh, undiluted human lung airway mucus (AM) isolated from extubated endotracheal tubes ${ }^{17}$ and in human cervicovaginal mucus (CVM) recovered from an inserted menstrual cup. ${ }^{18,19} \mathrm{lgG}$-mediated virion immobilization is attributed to the presence of multiple low-affinity bonds between the array of bound IgG to individual virions and mucins, ${ }^{18}$ specifically mediated by N-glycans on the Fc domain of lgG. Trapping in mucus directly precludes access to underlying cells, ${ }^{20}$ facilitates rapid elimination through natural mucus clearance mechanisms, ${ }^{17}$ and blocks vaginal Herpesvirus transmission in vivo. ${ }^{18}$ These findings underscore the ability for antibodies, either secreted by the immune system or topically delivered to mucosal surfaces, to reinforce the mucosal barrier against foreign pathogens.

Despite the strong evidence that lgG can trap viruses in $A M$ and CVM secretions, it remains unclear if topically delivered IgG could reinforce the barrier properties of GIM, particularly against highly motile bacterial pathogens. First, AM and CVM are composed primarily of MUC5B mucins (with modest levels of MUC5AC), whereas mucins produced locally in the Gl tract are comprised primarily of MUC2. ${ }^{3,9}$ Despite their biochemical similarity, members of the mucin family can vary considerably in length and sequence of tandem repeats, size, and glycosylation. ${ }^{21-23}$ Thus, it remains unproven whether lgG-Fc would possess the appropriate affinity to MUC2 and other mucins in GIM to enable crosslinking of pathogens to the mucin mesh. Second, although IgG is by far the dominant antibody, ${ }^{10,13}$ and substantial quantities of $\lg$ are present in $\mathrm{AM}^{12}$ the predominant antibody in GIM is secretory $\lg \mathrm{A}$ $(\operatorname{sg} A) .{ }^{11,24}$ This may be construed to implicate $\operatorname{sig} A$, and not $\lg G$, as the only suitable immunoglobulin in the Gl tract. Third, unlike

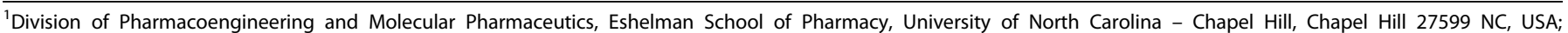

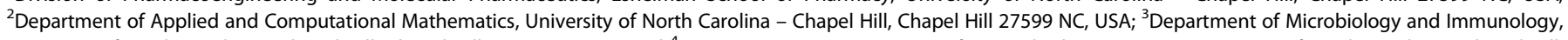

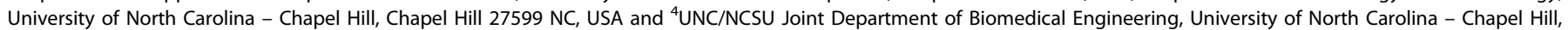
Chapel Hill 27599 NC, USA

Correspondence: Samuel K. Lai (lai@unc.edu)
}

Received: 19 September 2018 Revised: 10 December 2019 Accepted: 27 December 2019

Published online: 2 March 2020 
viruses that permeate mucus by undergoing Brownian motion in low viscosity interstitial fluids between the mucin mesh, actively motile bacteria can quickly swim through mucus. In turn, there is a much shorter time window for adequate number of antibody molecules to accumulate on the surface of the bacteria to immobilize the bacteria in the mucus gel, before the bacteria actually reaches the underlying epithelium. Further, there must be a much greater number of bound IgG on the bacterial surface to generate the additional avidity to counteract the forces generated by active flagella beating, compared to bound IgG on viruses whose motion is driven by thermal excitation.

To investigate whether IgG could reinforce GIM against active bacteria, we performed high-resolution video microscopy to capture how lipopolysaccharide (LPS)-binding IgG could alter the motion of fluorescent Salmonella enterica serovar Typhimurium (S. Typhimurium) in fresh GIM isolated from the mouse intestinal tract. Surprisingly, we found that lgG was able to arrest highly motile $S$. Typhimurium in GIM and markedly reduce the flux of Salmonella that could penetrate through mucus.

\section{RESULTS}

Anti-LPS IgG alters the distribution of Salmonella motility in mouse GIM

We collected fresh undiluted GIM from $R a g 1^{-1-}$ mice, which lack mature $B$ and $T$ lymphocytes, thus eliminating endogenous antibodies that might cross-react with $S$. Typhimurium surface antigens. ${ }^{25}$ Then, using high-resolution multiple particle tracking, we quantified the motion of fluorescent $S$. Typhimurium in GIM treated with either anti-LPS or anti-biotin lgG (control monoclonal anitbody [mAb]). In untreated GIM (no mAb) as well as treated with control $\mathrm{mAb}$ to a final concentration of $5 \mu \mathrm{g} / \mathrm{mL}$, determined to be physiologically relevant and sub-agglutinating concentrations in our experimental setting (Supplementary Fig. 1), there was substantial heterogeneity in the $S$. Typhimurium motion: some appeared to not move at all, some appeared to undergo undirected Brownian-like motion, and a substantial fraction exhibited large, directed displacements (Fig. 1a), in good agreement with previous reports. ${ }^{8,26,27}$ In contrast, in aliquots of GIM from the same mouse but treated with $5 \mu \mathrm{g} / \mathrm{mL}$ anti-LPS IgG, the collective motion of the $S$. Typhimurium appeared visually distinct. Specifically, there were substantially more bacterial traces reflecting hindered motion, and a reduced number of traces with long, directed displacements. Importantly, non-specific anti-biotin IgG (control $\mathrm{mAb}$ ) did not alter Salmonella mobility in mouse GIM (mGIM) compared to Salmonella mobility in the absence of exogenous mAb (no mAb, Supplementary Fig. 2).

Bacteria are known to undergo "run-and-tumble" motion: a bacteria can exhibit long-range active motility in one instant, and restricted tumbling motion the next instant. ${ }^{27,28}$ To robustly analyze the impact of anti-LPS IgG on S. Typhimurium motion in GIM, we developed a hidden Markov model framework capable of categorizing each time increment within a bacterial trace into one of three groups: "immobilized", "hindered/diffusive", or "swimming", as illustrated by their representative traces in Fig. 1a. Individual trace increments were classified using a three-state Markov process to model the state-dependent motion of bacteria. In the swim state, bacterial motion is directed in a random direction. In the hindered state, motion is undirected and diffusive. In the final immobilized state, motion is also undirected but greatly hindered. Using this framework, we were able to quantify how antibodies may impact the fraction of all incremental motion in the different motion states (i.e., \% increments), and also the dominant characteristic of individual bacterial path containing multiple increments (i.e., \% traces). In bacterial traces with directed motion, the presence of anti-LPS IgG markedly reduced the distance traveled by individual bacteria compared to control mAb (Fig. 1b). In matched mGIM samples, we observed a modest but statistically significant increase in the total number of trace increments defined as immobilized in the presence of anti-LPS IgG compared to control mAb. Specifically, of all trace increments measured, the percentage of increments categorized as "immobilized" increased from $35 \pm 12 \%$ in the anti-biotin control to $41 \pm$ $14 \%$ with anti-LPS IgG (Fig. $1 b,{ }^{*} p<0.05$ ). Similarly, the percent of increments classified as "hindered/diffusive" was increased from $48 \pm 7 \%$ in the control $\mathrm{mAb}$ condition to $53 \pm 11 \%$ in the presence of anti-LPS IgG. The greatest change was observed in the total number of trace increments classified as swimming between the two mAb conditions: anti-LPS IgG reduced the percentage of swimming increments by $73 \%$, from $16 \pm 10 \%$ (control $\mathrm{mAb}$ ) to $6 \pm 6 \%$ (Fig. $1 b,{ }^{* * * *} p<0.0001$ ).

Taking advantage of the hidden Markov model framework's capacity to classify individual trace increments into one of the three motion states on an increment-by-increment basis, we used maximum likelihood estimation ${ }^{29-32}$ to infer the average transition rates into or out of the different motion states (e.g., from immobilized to hindered, or swim to hindered, etc.), to further reveal the frequency and duration of which directed progressive motility can be sustained. We found that anti-LPS IgG markedly changed the bacteria's transition rates between directed (i.e., swimming) and undirected (hindered or immobilized) motion (Fig. 1c, d), but not the transition between the two undirected motion states (i.e., immobilized vs. hindered) (Supplementary Fig. 3). Specifically, the average rate of $S$. Typhimurium transitioning from the hindered to swim state decreased from $0.41 \pm 0.19$ transitions per second in control lgG to $0.25 \pm 0.12$ per second with anti-LPS lgG, indicating that anti-LPS lgG made it less likely for S. Typhimurium to initiate undergoing directed swimming motion with large displacements (Fig. $1 c^{* * * *} p<0.001$ ). Similarly, the average rate of $S$. Typhimurium transitioning from the swim to hindered motion state was markedly increased from $1.37 \pm 0.54$ per second in control lgG to $2.74 \pm 0.67$ per second with anti-LPS $\mathrm{lgG}$, indicating that the presence of anti-LPS IgG made it twice as likely for an actively swimming $S$. Typhimurium to stop swimming and transition to the hindered motion state (Fig. 1d, ${ }^{* * *} p<$ 0.0001). These observations imply that lgG-mediated tethering of bacteria to mucins may reduce the overall distance traversed by individual bacterium (by reducing the frequency and duration of large, directed displacements), thereby potentially limiting bacterial invasiveness.

To further substantiate this hypothesis, we performed additional studies capturing the motion of Salmonella bacteria in buffer containing native anti-LPS IgG, and showed that our anti-LPS IgG does not appreciably slow bacteria compared to control IgG (Supplementary Fig. 4).

Anti-LPS IgG decreases the amount of time Salmonella spend swimming with directed motion

Several studies have corroborated that bacteria moving in a tumbling or "undirected" fashion are less invasive than swimming bacteria moving with "directed" motion. ${ }^{26-28}$ Therefore, we sought to explore the effect of anti-LPS IgG on the most mobile $S$. Typhimurium populations in GIM. We stratified the most actively swimming population by sorting for Salmonella that remained swimming for the longest duration (i.e., bacterial traces that underwent swimming motion of at least five consecutive increments, or swimming for at least $\sim 330 \mathrm{~ms}$ at a time). The percentage of traces with extended-swimming bacteria decreased from $37 \pm 16 \%$ in the control $\mathrm{mAb}$ condition to $16 \pm 11 \%$ in the presence of anti-LPS IgG (Fig. $2 \mathrm{a},{ }^{* * *} p<0.0001$ ). Next, for these bacterial traces with sustained swimming motion, we calculated the percent of the time spent in the swimming state based on the total number of increments in each trace that were classified as swimming over the entire length of the trace (Fig. 2b). In GIM treated with anti-LPS IgG, bacteria spent a shorter fraction of time $(78 \pm 7 \%)$ in the swim state overall, compared to in 


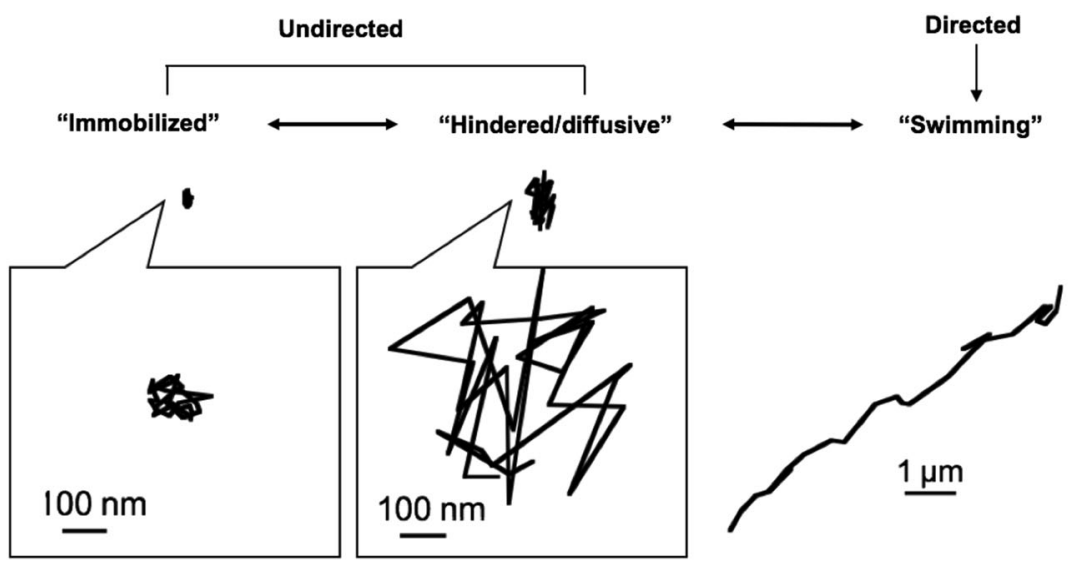

b

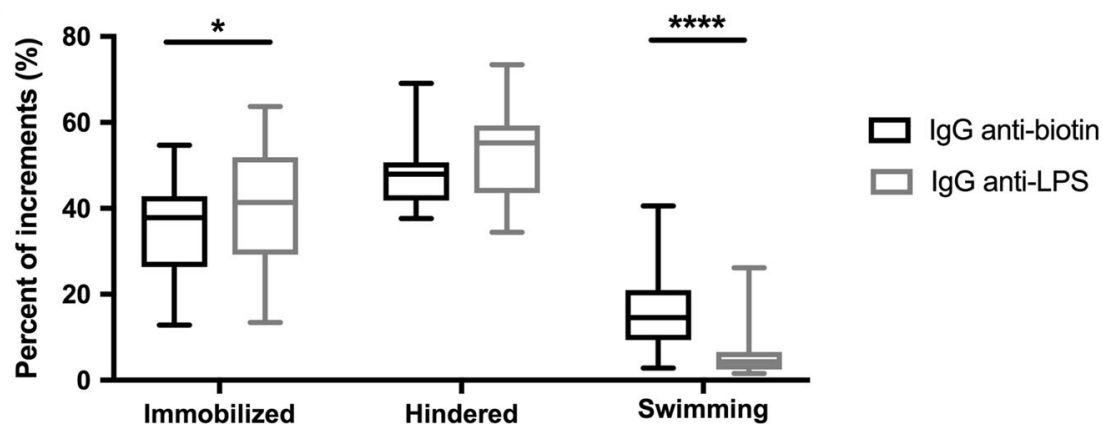

C

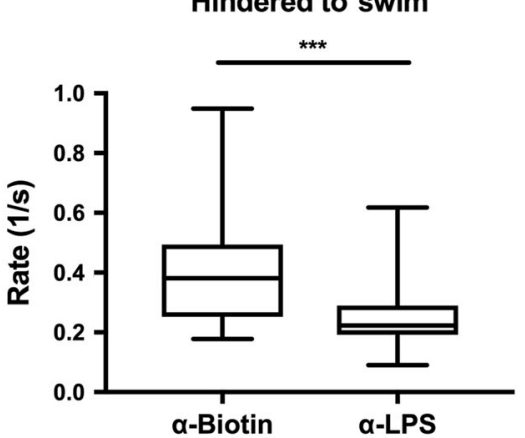

d

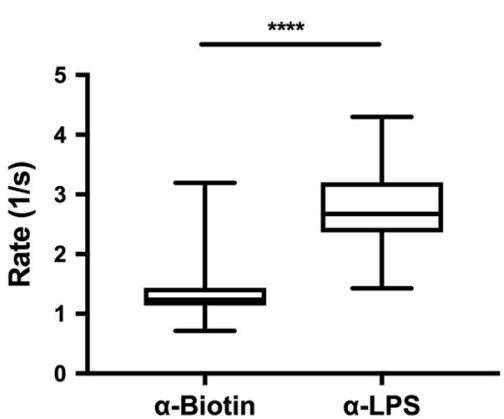

Fig. 1 Anti-LPS IgG alters the nature of Salmonella motility in mouse GIM. a Representative traces of bacteria exhibiting different states of motion (immobilized, hindered/diffusive, and swimming) over 30 consecutive frames. b Percent of total trace increments (i.e., incremental bacterial motion captured at the video frame rate) that are classified as immobilized, hindered, or swimming in the presence of either $5 \mu \mathrm{g} / \mathrm{mL}$ $\operatorname{lgG} 1$ anti-biotin or $5 \mu \mathrm{g} / \mathrm{mL} \operatorname{lgG} 1$ anti-LPS. c, d Average rate of Salmonella transitioning c from the hindered to swimming motion state and d from the swimming to the hindered motion state in the presence of either $5 \mu \mathrm{g} / \mathrm{mL}$ anti-biotin $\operatorname{lgG}{ }_{1}$ or $5 \mu \mathrm{g} / \mathrm{mL}$ anti-LPS $\mathrm{lgG}$. Box dimensions represent minimum, median, maximum, and interquartile range. Two-way ANOVA with Sidak's multiple comparison's test and Student's paired, two-tailed $t$ test $\left({ }^{*} p<0.05,{ }^{* *} p<0.01,{ }^{* * *} p<0.001,{ }^{* * * *} p<0.0001\right)$.

GIM treated with control mAb $(88 \pm 5 \%)$ to (Fig. $\left.2 b,{ }^{* * *} p<0.001\right)$. The average velocity of bacteria while in the swim state (velocity of swim increments) in the presence of anti-LPS IgG was $7.1 \pm 1.0 \mu \mathrm{m} / \mathrm{s}$ compared to $9.6 \pm 1.7 \mu \mathrm{m} / \mathrm{s}$ with control mAb (Fig. 2c, ${ }^{* * * *} p<0.0001$ ).

IgG-mediated trapping of Salmonella in mGIM is dependent on the Fc-glycan

We previously showed that $\mathrm{N}$-glycans on the asparagine-297 residue of the Fc region of IgG heavy chain are critical to IgG-mediated trapping of herpes simplex viruses in CVM. ${ }^{18}$ Therefore, we sought to explore whether lgG-mediated tethering of individual bacteria to the mucin matrix was mediated by the same mechanism. We used peptide $\mathrm{N}$-glycosidase $\mathrm{F}$, an enzyme with cleavage specificity for $\mathrm{N}$-linked glycans, to remove the Fc-glycan from the lgG heavy chain, and verified complete deglycosylation of the anti-LPS IgG using a concanavalin A (ConA)-specific western lectin blot (Fig. 3a). Deglycosylation of the anti-LPS IgG did not appear to appreciably alter its binding affinity to the $S$. Typhimurium (Fig. 3b).

Deglycosylation appeared to nearly completely eliminate the ability for anti-LPS IgG to immobilize $S$. Typhimurium, with the percent of swimming increments increasing nearly threefold $(18 \pm 10 \%)$ compared to in the native anti-LPS IgG condition $(6 \pm 6 \%)$ (Fig. $\left.3 c,{ }^{* *} p<0.001\right)$, but no statistically significant difference between deglycosylated anti-LPS IgG and control mAb. In addition, the rate of $S$. Typhimurium transition from the hindered state to the swim state was much greater $(0.42 \pm 0.24 / \mathrm{s}$ vs. $0.26 \pm 0.13 / \mathrm{s}$ ) (Supplementary Fig. $3 c,{ }^{* *} p<0.01$ ), and the transition rate from swim to hindered state lower $(1.3 \pm 0.39 / \mathrm{s}$ vs. $2.7 \pm 0.56 / \mathrm{s}$ ) for native anti-LPS IgG compared to its deglycosylated 

swimming motion

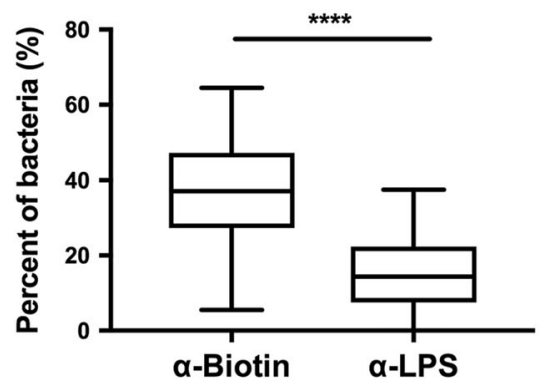

Percent of time spent swimming

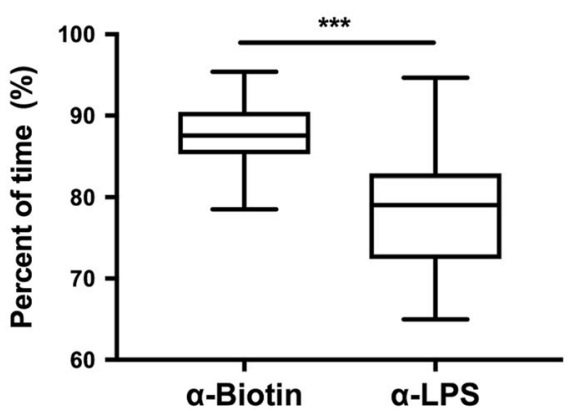

Velocity of swim increments

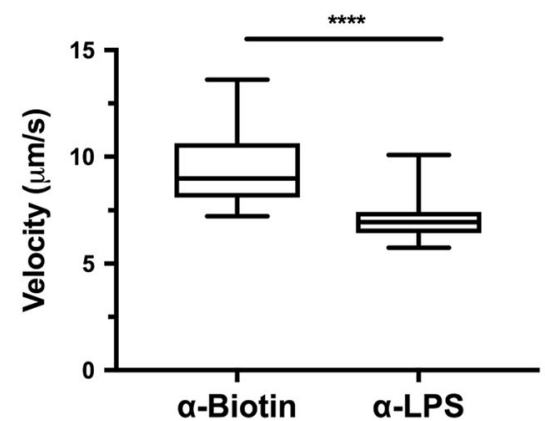

Fig. 2 LPS-specific IgG $\mathbf{~}_{1}$ decreases the amount of time Salmonella spend swimming in GIM. a Percent of total bacterial traces where the bacteria were classified as swimming by a Markov model analysis for at least five consecutive increments, which we categorized as undergoing extended-swimming motion, b percent of time spent in the swimming state by bacteria exhibiting possessing at least five consecutive frames of swimming motion (extended swimming), and c average swim velocity of all trace increments classified as swimming increments in the consecutively swimming bacterial population in the presence of either $5 \mu \mathrm{gg} / \mathrm{mL}$ anti-biotin lgG $\mathrm{gr}_{1} 5 \mu \mathrm{g} / \mathrm{mL}$ anti-LPS $\operatorname{lgG}_{1}(N=18 \mathrm{mGIM}$ samples). Box dimensions represent minimum, median, maximum, and interquartile range. Student's paired, two-tailed $t$ test $\left({ }^{*} p<0.05,{ }^{* *} p<0.01,{ }^{* * *} p<0.001,{ }^{* * * *} p<0.0001\right)$.

counterpart (Supplementary Fig. 3d, ${ }^{* * *} p<0.0001$ ). Ultimately, the lack of changes in these transition rates resulted in an overall greater amount of time spent swimming by $S$. Typhimurium in the deglycosylated anti-LPS IgG and control mAb conditions compared to in the native anti-LPS IgG condition (Fig. 3e, ${ }^{* * *} p<0.001$ ). Finally, deglycosylated anti-LPS IgG failed to reduce the fraction of bacteria undergoing extended-swimming motion (Fig. 3d, ${ }^{* * *} p<$ 0.001 ), as well as the velocity of those bacteria while in the swimming state compared to native anti-LPS IgG $(9.7 \pm 2.0$ vs. $7.1 \pm 0.7 \mu \mathrm{m} / \mathrm{s}$, Fig. $\left.3 \mathrm{f},{ }^{* * *} p<0.001\right)$. All observations in the deglycosylated anti-LPS IgG condition were indistinguishable from control lgG, strongly implicating the involvement of Fc Nglycans in IgG-mucin crosslinking.

Anti-LPS IgG limits Salmonella penetration across mGIM in an Fcglycan-dependent manner

The protective properties of mucus are naturally dependent on the thickness of the barrier, and minimizing the fraction of pathogens that penetrate this layer may in turn reduce the probability of infection. ${ }^{33}$ We first used in silico modeling to evaluate the potential effectiveness of lgG-mediated trapping of S. Typhimurium in $\mathrm{mGIM}$, based on the experimental measurements above. Using parameters derived from hidden Markov simulations (see Table in Methods section), we calculated the firstpassage times (i.e., the fraction of Salmonella that would theoretically penetrate a GIM layer of physically defined thickness over time ${ }^{33,34}(0-1000 \mu \mathrm{m})$ under different lgG-treated conditions (Fig. 4). We found that the fraction of S. Typhimurium that could penetrate the GIM layer over at least the first $5 \mathrm{~h}$ was significantly reduced by $\lg G 1$ anti-LPS across all theoretical mucus thicknesses (Fig. 4c), while bacterial penetration by Salmonella in the presence of deglycosylated anti-LPS IgG (Fig. 4b) was indistinguishable from control lgG (Fig. 4a). For instance, extrapolating from the plotted simulations, in a $250-\mu \mathrm{m}$-thick mucus layer, native anti-LPS IgG reduced the fraction of $S$. Typhimurium permeating GIM within $2 \mathrm{~h}$ by about four-fold, to $\sim 15 \%$ compared to $\sim 90 \%$ in both the control mAb and deglycosylated anti-LPS IgG conditions (Supplementary Fig. 5). With greater GIM thicknesses, for example, $500 \mu \mathrm{m}$, few if any $S$. Typhimurium would be able to permeate GIM containing $5 \mu \mathrm{g} / \mathrm{mL}$ anti-LPS IgG within $5 \mathrm{~h}$, vs. nearly $75 \%$ of $S$. Typhimurium in GIM containing control $\mathrm{mAb}$ or deglycosylated anti-LPS lgG (Supplementary Fig. 5).

To validate our in silico observations experimentally, we developed a transwell assay using fresh, undiluted mGIM with the experimental setup illustrated in (Fig. 5a). In good agreement with our expectations, native anti-LPS IgG markedly reduced
S. Typhimurium translocation across an $\sim 10-\mathrm{mm}$-thick mucus layer over $4 \mathrm{~h}$ in a dose-dependent manner (Fig. 5c), while deglycosylated anti-LPS IgG failed to limit bacterial penetration (Fig. 5b). Salmonella growth was not impaired in the presence of anti-LPS $\lg \mathrm{F}(\mathrm{ab})$ up to $10 \mu \mathrm{g} / \mathrm{mL}$, implying that lgG binding to $S$. Typhimurium did not induce bacterial death or inhibit bacterial growth over time (Fig. 5d). Additionally, when the transwell assay was repeated with increasing concentrations of anti-LPS IgG F(ab) $(0-10 \mu \mathrm{g} / \mathrm{mL})$, Salmonella retained its capacity to penetrate $\mathrm{mGIM}$ (Fig. 5e). This indicates that the $F(a b)$ arms alone are insufficient to directly inactivate active motility. Together, these results further validate the requirement for both antigen specificity and interaction of the $\mathrm{Fc}$ region with the mucus gel for effective Ab-mediated trapping of pathogens in mucus. Consistent with this hypothesis, native anti-LPS IgG only trap Salmonella in the presence of mucins, and not in buffer, which further implicates the role of IgG-mucin interactions (Supplementary Fig. 4).

\section{DISCUSSION}

The human intestinal tract is exposed to an abundance of diverse microorganisms. As the largest mucosal surface in the body, the gut mucosal immune system faces a constant battle between eliminating potential pathogens and maintaining homeostasis with commensal microbes. ${ }^{24,35}$ An abundance of antibodies (particularly slgA) are secreted into GIM to maintain this mutually beneficial relationship. Recent work is beginning to shed light on the protective role of slgA in mucus, including immune exclusion based on slgA-induced agglutination, resulting in bacteria-sigA complexes that are too large to permeate $\mathrm{GIM}^{35}$ Interestingly, IgA deficiencies occur on the order of 1 in 300 to 1 in 600 people, ${ }^{36}$ yet the vast majority of IgA-deficient individuals ( $~ 85-90 \%)$ remain asymptomatic. This suggests that other lgs, such as $\lg M$ or $\lg G$, can likely compensate for part of slgA function in mucosal protection. ${ }^{37}$ Additionally, IgG can enter the lumen of the GI tract during infection and have a significantly beneficial effect in combatting the infection. ${ }^{38}$ Here, consistent with that hypothesis, we show for the first time that IgG is capable of fortifying the GIM barrier against highly motile bacteria at physiologically relevant, subagglutinating concentrations of $\mathrm{lgG}$. Specifically, the array of IgG bound to an individual bacteria can crosslink the bacteria to the mucin mesh via N-glycans on IgG-Fc. While the affinity of individual lgG molecules with mucins is low, the high valency of anti-LPS antibodies binding to many epitopes, combined with the relatively large surface area, which these epitopes are displayed across the surface of the bacteria, results in a high avidity of 
a

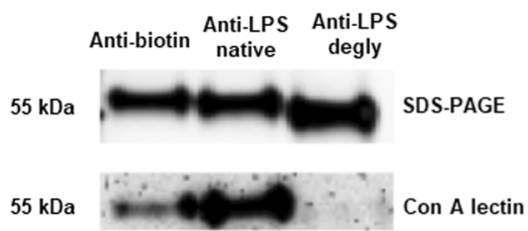

d Bacteria undergoing extended swimming motion

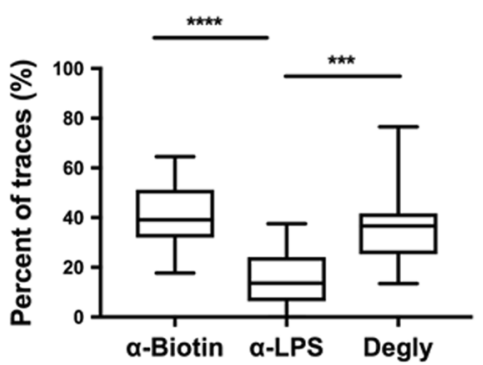

b

Binding of IgG1 anti-LPS to S. typhimurium

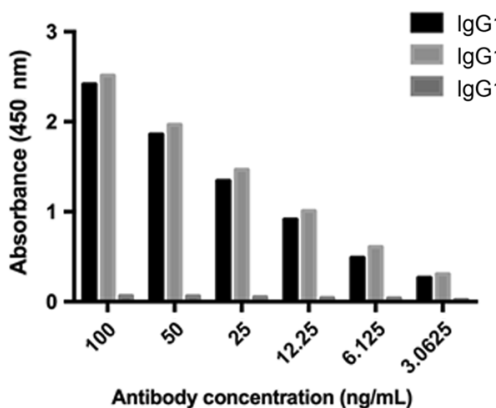

e

Percent of time swimming

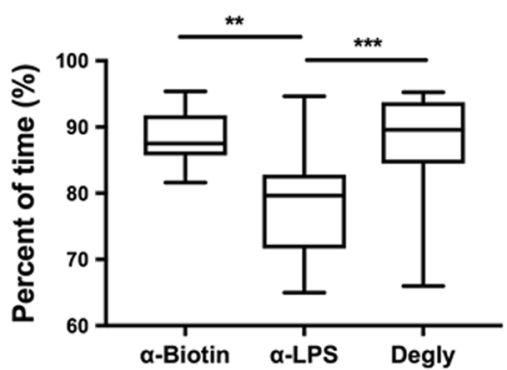

gG1 LPS native G1 LPS degly gG1 biotin

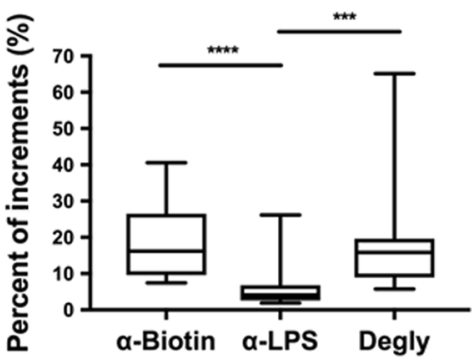

f

Velocity of swim increments

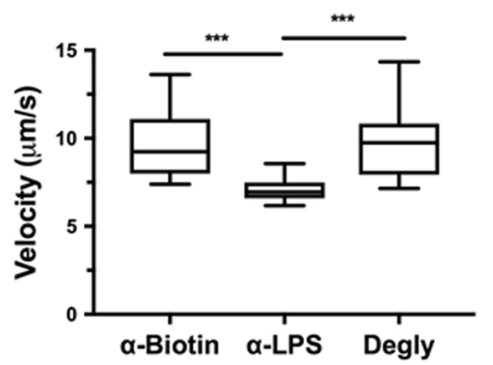

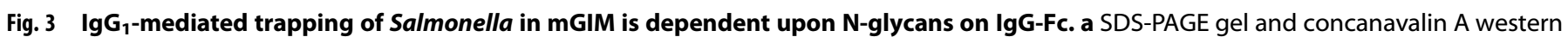
lectin (specific for high-mannose structures) confirming successful deglycosylation of IgG1 anti-LPS, indicated by a shift in MW and negative

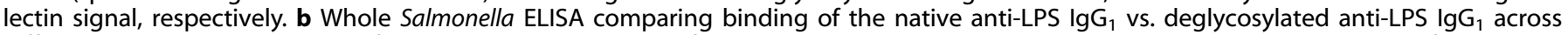
different IgG concentrations confirms that deglycosylation of anti-LPS lgG 1 did not impair binding to Salmonella. c Percent of total trace increments that are classified as swimming, $\mathbf{d}$ percent of total bacterial traces that exhibited swimming motion for at least five consecutive increments, categorized as undergoing extended-swimming motion, e percent of time spent in the swim state by bacteria undergoing extended-swimming motion, and $\mathbf{f}$ average swim velocity of all increments classified as swimming for bacteria undergoing extendedswimming motion in the presence of either $5 \mu \mathrm{g} / \mathrm{mL}$ of anti-biotin $\mathrm{lgG}, 5 \mu \mathrm{g} / \mathrm{mL}$ of deglycosylated anti-LPS IgG 1 , or $5 \mu \mathrm{g} / \mathrm{mL}$ of native anti-LPS $\mathrm{IgG}_{1}$. Box dimensions represent minimum, median, maximum, and interquartile range $(N=13)$. One-way ANOVA with Tukey's multiple comparisons test $\left({ }^{*} p<0.05,{ }^{* *} p<0.01,{ }^{* * *} p<0.001,{ }^{* * * *} p<0.0001\right)$.
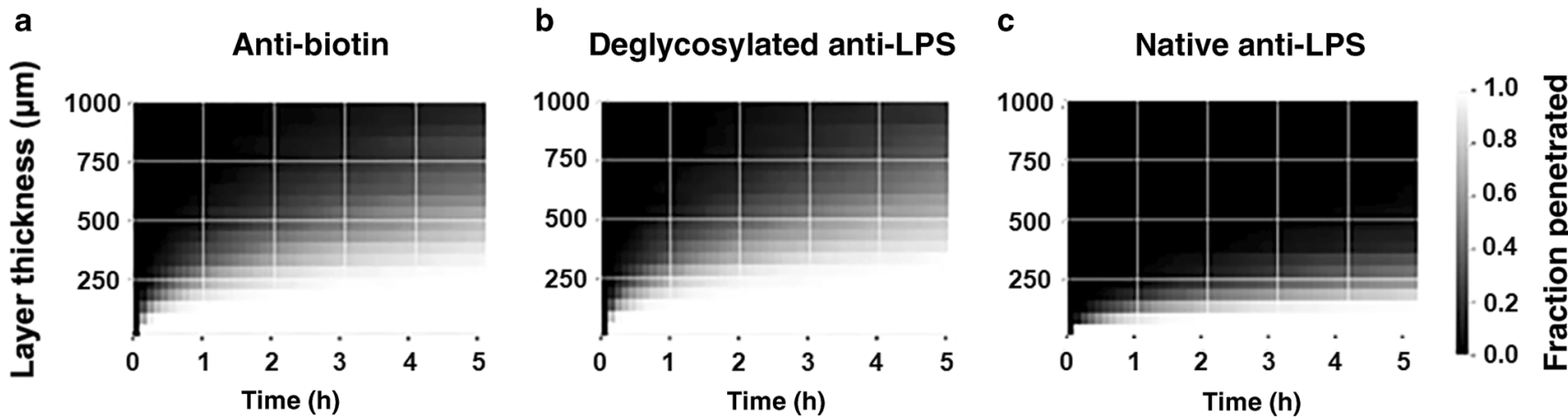

Fig. 4 Simulated first-passage time (FPT) analysis of Salmonella penetration across mouse gastrointestinal mucus of varying thickness. a FPT analysis displaying the fraction of Salmonella capable of penetrating a mGIM layer of thicknesses $0-1000 \mu \mathrm{m}$ over $5 \mathrm{~h}$ in the presence of (a) anti-biotin $\operatorname{lgG}_{1}(5 \mu \mathrm{g} / \mathrm{mL})$, (b) deglycosylated anti-LPS $\operatorname{lgG}_{1}(5 \mu \mathrm{g} / \mathrm{mL})$, and (c) native anti-LPS $\operatorname{lgG}{ }_{1}(5 \mu \mathrm{g} / \mathrm{mL})$.

the lgG-mucin interaction, which can accomplish bacterial immobilization (Fig. 6). ${ }^{14-16}$ Consequently, this increases the rate of bacteria transitioning from swimming to tumbling/diffusive states, decreases the duration of extended-swimming motion, and reduces their swimming velocity.

Several studies have shown that disruption of bacterial motility attenuates disease and reduces bacterial invasiveness. ${ }^{26-28,39}$ Stecher et al. ${ }^{26}$ determined that $S$. Typhimurium with mutations in flagellar machinery had reduced fitness, while flagellated sub-populations accumulated at the epithelium. Similarly, Pontier-
Bres et al. ${ }^{28}$ showed that mutant strains of $S$. Typhimurium exhibiting "smooth" swimming patterns were more invasive than mutants with "tumbly" swimming patterns, and more effective at entering Peyer's patches in an intestinal loop model. Finally, Le Moal et al. ${ }^{27}$ showed that inhibition of S. Typhimurium swimming motility led to delayed entry into human mucus-secreting HT29MTX cells. Given the body of literature that describes the impaired invasiveness of slowed or immobilized Salmonella, particularly the observation that non-motile mutants of $S$. Typhimurium are $30-50$-fold less invasive than their parental wild-type strains, ${ }^{35,40,41}$ 
a
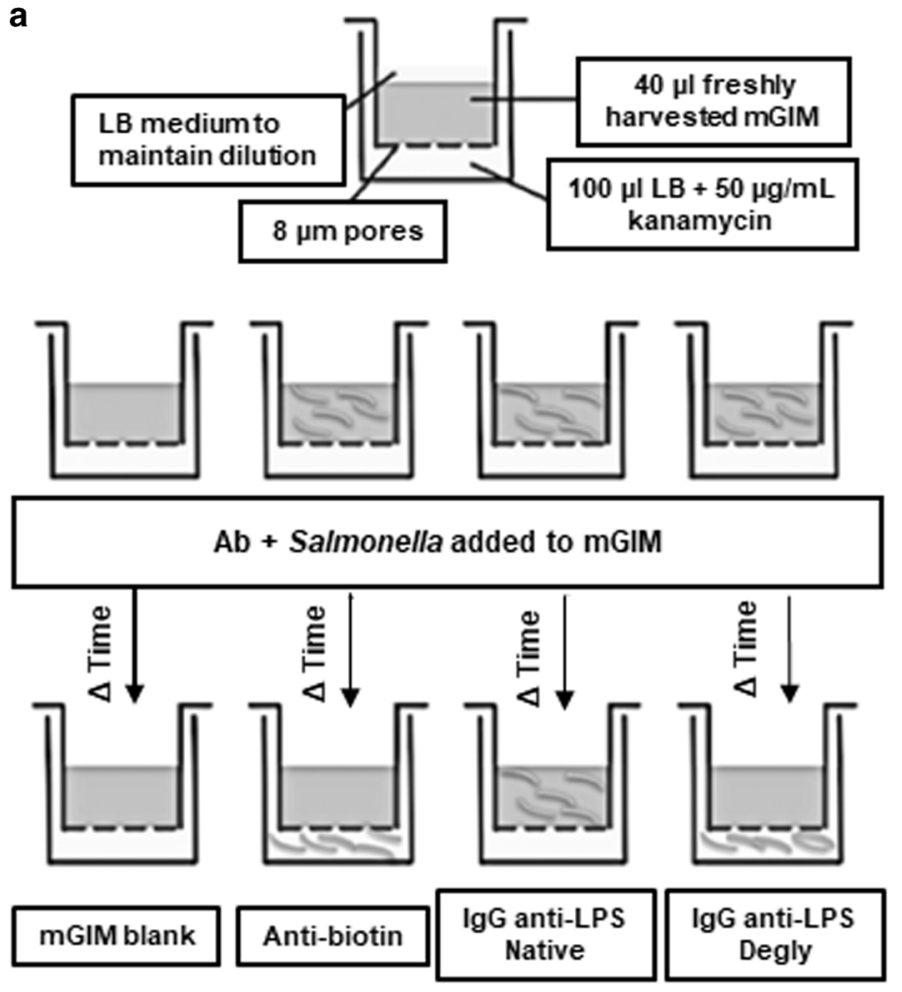

b
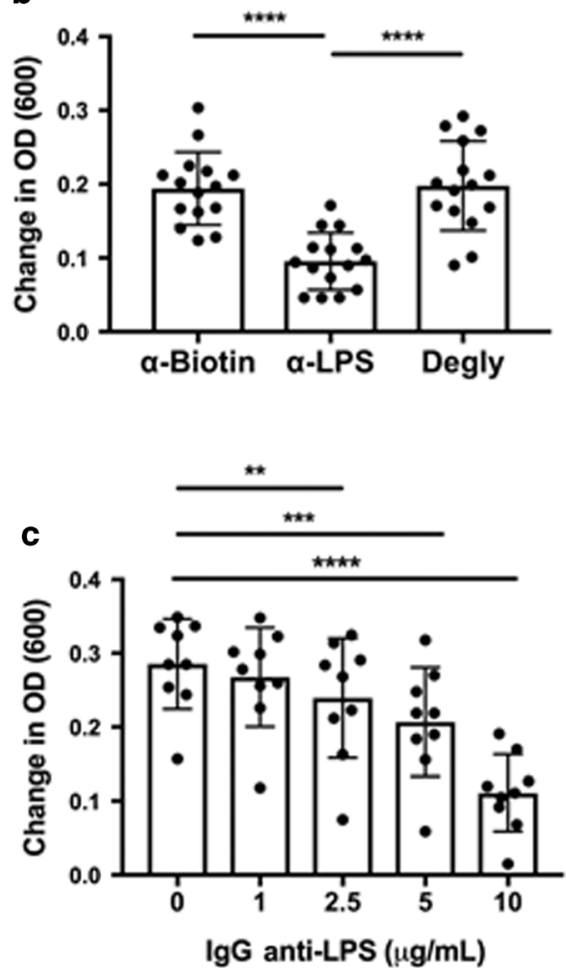

d

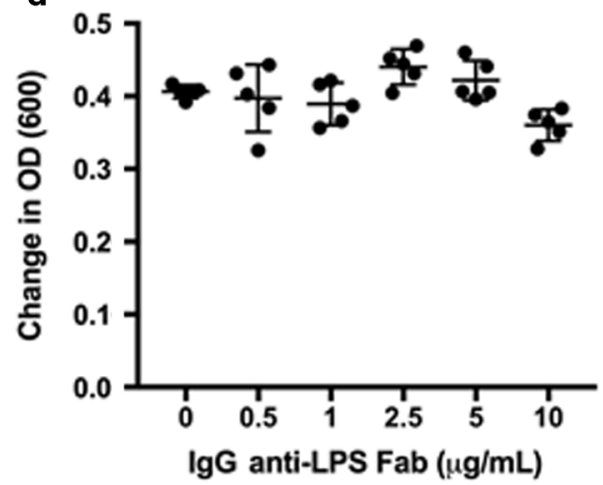

e

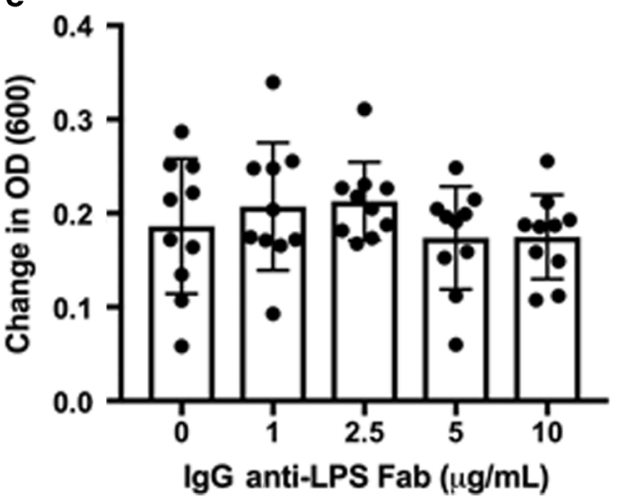

Fig. 5 Salmonella penetration across mouse gastrointestinal mucus ex vivo. a Schematic of transwell assay to evaluate Salmonella penetration across $\mathrm{mGIM}$ ex vivo in the presence anti-biotin $\lg _{1}$, native anti-LPS Ig $\mathrm{G}_{1}$, or deglycosylated anti-LPS IgG ${ }_{1}$. b Optical density $\left(\mathrm{OD}_{600}\right)$ of Salmonella in the receptor compartment demonstrates that $5 \mu \mathrm{g} / \mathrm{mL}$ of native anti-LPS IgG1 in mucus markedly reduces bacterial penetration across GIM compared to control lgG and deglycosylated lgG. c The reduction in Salmonella penetration across mGIM is dependent on IgG concentration. d Bacterial growth assay, based on optical density of bacterial cultures in the presence of increasing concentrations of anti-LPS Fab, shows that LPS-binding antibody is non-bactericidal to Salmonella. e Transwell assay with increasing concentrations of anti-LPS IgG Fab shows that binding antibodies alone did not reduce bacterial translocation across mGIM. Data shown represents Salmonella growth at $4 \mathrm{~h}$. Mean \pm SD. One-way ANOVA with Tukey's multiple comparisons test $\left({ }^{*} p<0.05,{ }^{* *} p<0.01,{ }^{* * *} p<0.001,{ }^{* * *} p<0.0001\right)$.

we speculate that the muco-trapping effector function of lgG, may protect against bacterial infection in the $\mathrm{Gl}$ tract by reducing bacterial flux across GIM.

Progressive motility through mucus is likely integral to mucosal colonization. ${ }^{7}$ The flagellar motor generally rotates counterclockwise, propelling the cell forward with directed motion. In contrast, when flagella switch to a clockwise direction, bacteria may enter a transiently tumbling state. ${ }^{8,9}$ These results suggest targeting flagellum beating may be an effective strategy to reduce bacterial permeation across a mucus layer. For example, it was previously shown that mannose-binding lectin (MBL) reduced swimming speed and overall motile fraction of Salmonella due to reduced the flagellar rotation rate attributed to a change in intracellular $\mathrm{pH}$ and membrane potential. ${ }^{8}$ Similarly, Forbes and colleagues $^{1}$ showed that an $\mathrm{O}-5$-specific monoclonal $\lg \mathrm{A}$ against Salmonella (Sal4) as well as polyclonal anti-LPS lgG both directly inhibited flagellum-based Salmonella motility in agar motility assays independent of agglutination. Another LPS-specific $\operatorname{lgA}$ (2D6), as well as its corresponding monovalent lgG Fab fragment, also inhibited flagellum-based motility of Vibrio cholerae in both semisolid agar and liquid medium due to flagellum-flagellum crosslinking, leading to flagellar entanglement and consequently, motility arrest. ${ }^{2}$ In the same study, Levinson et al. ${ }^{42}$ reported that monovalent 2D6 IgG Fab fragments inhibited $V$. cholerae motility by a similar mechanism. Despite similarities in the use of mAb to alter bacterial motion, we believe our observed trapping in mouse 
820

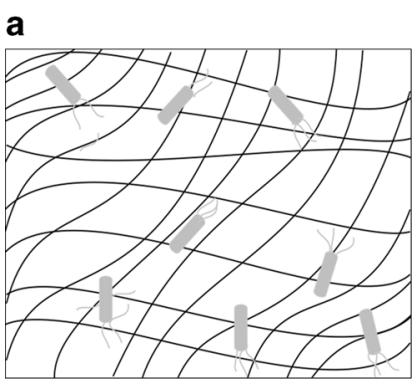

Pathogen active b

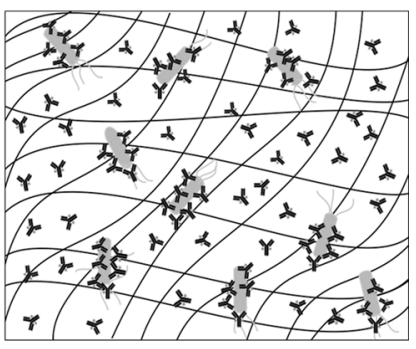

Pathogen immobilized
Fig. 6 Proposed schematic of Ab-mediated trapping of Salmonella in mGIM. a In the absence of Salmonella binding antibodies, Salmonella will transition between directed (swimming) motion states and undirected motion state as they readily penetrate through mucus. b In mucus-containing anti-LPS Ig ${ }_{1}$, IgG quickly accumulate on the surface of individual Salmonella bacteria, which generates sufficient avidity between the bacteria/lgG complex and the mucin mesh to markedly reduce the frequency with which Salmonella can assume and maintain swimming motion, thereby greatly reducing the flux of bacteria that can penetrate through mucus.

GI mucus is caused by a distinct mechanism. Indeed, MBL reduced the total fraction of Salmonella exhibiting swimming motility by $\sim 15 \%$, compared to a $73 \%$ reduction observed here with anti-LPS IgG in mucus. More importantly, since we observed no appreciable difference in Salmonella motility using deglycosylated antiLPS IgG vs. untreated control, the anti-LPS IgG could not have directly crosslinked flagellum or otherwise directly inactivated flagellum-based motility. An anti-LPS F(ab) was also insufficient to alter Salmonella motility, which indicates that the $F(a b)$ portion of the $A b$ is unable to directly inactivate bacterial motion and the Fc region is required. These results suggest that the observed arrest in bacterial motility is due to N-glycans on IgG-Fc mediated tethering to mucins, rather than biochemical interference with flagella. ${ }^{8}$ Unpublished studies investigating lgG-mediated trapping of foreign particles in alginate vs. agarose suggests lgG$\mathrm{N}$-glycans likely form hydrogen bonds with carboxylic acid groups on biopolymer matrices to facilitate trapping; we believe IgG-Fc Nglycans most likely interact with $\mathrm{COOH}$ groups along mucins to trap bacteria in mucus, due to their abundance on mucins.

Members of the mucin family can vary considerably in length and sequence of tandem repeats, size, and glycosylation, ${ }^{21,23}$ and different mucins are dominant in the Gl tract vs. the lung airways or the female reproductive tract. ${ }^{11-13,24}$ Despite these differences, this work, coupled with our earlier discoveries of IgG-mediated trapping of viruses in both $\mathrm{AM}$ and $\mathrm{CVM},{ }^{17,18}$ suggests that IgG can reinforce the barrier properties of mucus at all major mucosal surfaces, supporting lgG-mucin crosslinking as a universal effector function of $\operatorname{lgG}$ at the first line of defense against pathogen invasion. This also implies that lgG-Fc is likely to bind to a target conserved feature among different mucins. Given that mucin is $\sim 80 \%$ sugar by weight, ${ }^{23}$ it appears likely that IgG-mucin crosslinking is likely mediated by interactions between Fc Nglycans and glycans on mucins. Despite our observations that even modest concentration of IgG can trap motile Salmonella bacteria in mucus, the precise number of bound Abs needed to immobilize individual bacteria remains elusive. Individual $\mathrm{mAb}$ on a trapped bacteria cannot be readily visualized by fluorescence microscopy, and bacteria also divide over time. Furthermore, IgG can associate with cellular structures (cell debris, shed epithelial cells), suggesting that at any given time, antigen-specific Abs may be pathogen bound, freely diffusing, or cell associated ${ }^{43}$ (Fig. 6).

Monoclonal antibodies are a highly effective class of biotherapeutics, typically administered via parenteral routes due to their instability in the Gl tract. Nevertheless, oral administration of mAbs may be an effective tool to prevent enterobacterial infection. ${ }^{44-46}$ The most critical factor influencing successful passive immunization of the gut is delivery of sufficient quantities of active antibody, which can be influenced by gastric $\mathrm{pH}$, protease activity, and $\mathrm{Gl}$ residence time. ${ }^{44}$ Antibodies are gradually inactivated and degraded when exposed to gastric fluids containing proteolytic enzymes such as pepsin and elastase. ${ }^{44,46}$ To overcome these unfavorable biochemical conditions, researchers are developing oral deliver formulations that preserve therapeutic $\mathrm{mAb}$ bioactivity. ${ }^{44,45,47}$ For instance, hydrogels encapsulating antibodies afforded greater mAb stability in the Gl tract compared to mAb alone. $^{44}$ Several studies have shown that $\lg A$ is capable of arresting bacterial motility, ${ }^{35,48}$ due to their limited availability and propensity to immobilize pathogens by agglutination, 11,24,40 we did not examine the ability of IgA anti-LPS to retard Salmonella mobility in mGIM. Moreover, in the context of translational development, lgG is currently the most widely used antibody isotype for biological applications. ${ }^{49,50}$

While overcoming the chemical barriers of the Gl tract may present a challenge, there are a number of advantages to oral antibody delivery. Parenteral routes of administration require large doses of antibody to confer protection, making mAb therapies expensive and inaccessible. ${ }^{46}$ Oral dosage forms to treat local infections in the $\mathrm{Gl}$ tract could have reduced cost due to reduced total quantities of $\mathrm{mAb}$ (by concentrating mAb directly at the site needed), as well as more relaxed sterility and formulation requirements for oral vs. systemic administration. In addition, oral delivery minimizes the risks of serious adverse side effects. ${ }^{45}$ For conditions affecting the gut in particular, higher concentrations of systemic $A b$ are likely needed to achieve protective concentrations in $\mathrm{GIM}^{41,45,50}$ thus increasing the risks of systemic side effects. We found that concentrations as low as $5 \mu \mathrm{g} / \mathrm{mL}$ anti-LPS significantly impacted the actively moving population of bacteria in GIM. At these concentrations, oral passive immunization may be a cost-effective and efficacious strategy to prevent/treat $\mathrm{Gl}$ infections. ${ }^{51,52}$

\section{MATERIALS AND METHODS}

Mice

Animals were purchased from Jackson Laboratory (C57B/6J, Stock No. 000664; B6.129S7-Rag1, Stock No. 002216). Mice were bred and maintained at the University of North Carolina-Chapel Hill animal facility. All mice were age and sex matched, and used between 8 and 10 weeks of age. All experiments were approved by University of North Carolina Institutional Animal Care and Use Committee (IACUC ID 15-327).

\section{GIM collection}

Mice were fasted for $4 \mathrm{~h}$ to reduce the amount of luminal solid content in the $\mathrm{Gl}$ tract before being sacrificed for mucus collection. The small intestine was excised and slit open length wise. To collect GIM, the smooth surface of a glass capillary pipette (Wiretrol ${ }^{\oplus}$, Drummond Scientific) was used to gently scrape along Gl tissue surface. Any remaining fecal solids were separated and mGIM was kept in a microcentrifuge tube on ice or at $4{ }^{\circ} \mathrm{C}$ until use within 24 h. $^{53}$

\section{Bacterial strain and growth condition}

The bacterial strain used in this study was a non chromosomally inserted green fluorescent protein (GFP)-expressing Salmonella Typhimurium SL1344 (provided by Dr. Ed Miao at the University of North Carolina Chapel Hill). SL1344-pGFP was grown overnight at a shaking rate of 200 r.p.m. at $37^{\circ} \mathrm{C}$ in Luria-Bertani (LB) broth supplemented with $50 \mu \mathrm{g} / \mathrm{mL}$ kanamycin for 14-16 h. Prior to microscopy, bacteria were diluted 1:10, and sub-cultured for an additional $2.5 \mathrm{~h}$ to ensure bacterial motility. Optical density 
$\left(\mathrm{OD}_{600}\right)$ was measured using a NanoDrop One instrument from Thermo Scientific. Bacterial motility in buffer was verified using a fluorescence microscope prior to study in mucus.

Sample preparation for particle tracking studies

Mucus slides for particle tracking were prepared using a custommade, $10-\mu \mathrm{L}$ slide chamber. Whole mucus was measured using a 20- $\mu \mathrm{L}$ glass capillary pipette. Five microliters of $\mathrm{mGIM}$ were transferred to the center of the slide chamber. Then, $2.5 \mu \mathrm{L}$ of either mouse IgG1 anti-LPS (Virostat 6331; specific for Salmonella Typhimurium by whole-cell enzyme-linked immunosorbent assay [ELISA]) or mouse IgG1 anti-biotin (Vector Labs MB-9100) were pipetted directly onto the surface of the mucus and mixed into the sample by gently stirring with a pipette tip to ensure uniform distribution. Next, $2.5 \mu \mathrm{L}$ of motile Salmonella culture was added to the mixture and again gently stirred. The final antibody concentration in mucus was $5 \mu \mathrm{g} / \mathrm{mL}$. The lgG concentration was selected based on pilot studies that showed no appreciable slowdown of bacteria at $\sim 1 \mu \mathrm{g} / \mathrm{mL}$. An lgG concentration of $\sim 5 \mu \mathrm{g} /$ $\mathrm{mL}$ is also comparable to what Michetti and colleagues ${ }^{6}$ previously reported as being necessary to block serovar Typhimurium invasion of intestinal epithelial cells (Supplementary Fig. 1). A coverslip was used to seal the well without significant compression of the mucus surface, and quickly sealed with superglue to minimize sample dehydration. Prepared slides were incubated at $37^{\circ} \mathrm{C}$ for $15-30$ min prior to imaging.

Fluorescence particle tracking microscopy

We used high-resolution multiple particle tracking to record and quantify the motion of hundreds of individual fluorescent Salmonella Typhimurium in mGIM. Specifically, the translational motions of the bacteria were recorded using an EMCCD camera (Evolve 512; Photometrics, Tucson, AZ) mounted on an inverted epifluorescence microscope (AxioObserver D1; Zeiss, Thornwood, NY), equipped with an Alpha Plan Apo $\times 100 / 1.46$ NA objective, environmental (temperature and $\mathrm{CO}_{2}$ ) control chamber, and an LED light source (Lumencor Light Engine DAPI/GFP/543/623/690). Videos $(512 \times 512,16$-bit image depth) were captured with the MetaMorph imaging software (Molecular Devices, Sunnyvale, CA) at a temporal resolution of $66.7 \mathrm{~ms}$ and spatial resolution of $10 \mathrm{~nm}$ (nominal pixel resolution $0.156 \mu \mathrm{m} /$ pixel) for $10 \mathrm{~s}$. At least five independent videos were captured per sample to ensure that bacteria were well distributed over the entire surface. Trajectories of at least 50 individual bacteria were analyzed for each condition. ${ }^{54}$ All experiments were performed at $37^{\circ} \mathrm{C}$.

\section{Analysis of Salmonella motion}

Image stacks acquired as described above were analyzed to extract the $x$ and $y$ positions of each Salmonella over time using a recently developed convolutional neural network. ${ }^{34}$ Image stacks where directional drift of all particles was observed were excluded from analysis. This was determined visually by watching the timelapse images and noting when all particles in the field moved in the same direction. To classify each increment of each track as either swimming, tumbling, or immobilized, we employed the widely used hidden Markov model framework, with the expectation-maximization algorithm for all. ${ }^{29-32}$ We used a threestate Markov process to model the state-dependent motion of bacteria. The three motion states are swimming, where motion is directed with a random direction, tumbling, where motion is undirected and diffusive, and immobilized, where motion is also undirected and substantially hindered. We did not constrain the model to assign a smaller diffusion coefficient to the stuck state; nevertheless, the maximum likelihood stage of the expectationmaximization algorithm selected a diffusivity that was $\sim 10$ times less than the tumbling state (Table 1). Motion in the swimming state was modeled as directed with a single speed magnitude and a three-dimensional random direction. The random direction was
Table 1. Maximum likelihood parameter estimates.

\begin{tabular}{llllll}
\hline & $k_{1}$ & $k_{2}$ & $k_{3}$ & $k_{4}$ & Swim speed \\
\hline No exogenous Ab & 0.57 & 0.49 & 0.37 & 1.2 & 18.7 \\
Anti-biotin IgG & 0.61 & 0.47 & 0.37 & 1.3 & 18.1 \\
Anti-LPS IgG & 0.56 & 0.50 & 0.25 & 2.4 & 15.3 \\
Anti-LPS IgG degly & 0.57 & 0.48 & 0.39 & 1.3 & 18.6 \\
\hline
\end{tabular}

selected uniformly over the unit sphere upon each transition from the hindered state into the swimming state. In total, the model contained eight parameters: the swim speed, the three-statespecific diffusion coefficients, and four transition rates controlling the stochastic dynamics of switching between the three motion states. Transitions were allowed bidirectionally between the stuck and hindered states and between the hindered and swim states.

Whole Salmonella ELISA to assess anti-LPS Ab binding efficiency Salmonella was cultured as described above. In a 96-well half-area ELISA plate, sample wells were coated with $1 \times 10^{8}$ colony-forming unit (CFU) in $100 \mu \mathrm{L}$ of LB using the conversion factor: $\mathrm{OD}_{600}=1=$ $1 \times 10^{9} \mathrm{CFU} / \mathrm{mL}$, followed by ultraviolet inactivation for $1 \mathrm{~h}$ and overnight incubation at $4{ }^{\circ} \mathrm{C}$. Plates were washed $5 \times$ with $0.05 \%$ phosphate-buffered saline (PBS)-Tween (PBST) and blocked with $170 \mu \mathrm{L}$ of $5 \%$ milk in PBST for $1 \mathrm{~h}$ at room temperature (RT). lgG1 anti-LPS native (Virostat 6331) and IgG1-LPS deglycosylated were prepared at $250 \mathrm{ng} / \mathrm{mL}$ in $1 \%$ milk in PBST. Standard curves were prepared by two-fold serial dilution. Mouse anti-biotin lgG1 (Vector Labs MB-9100) was used as an isotype control. Samples were incubated for $1 \mathrm{~h}$ at RT, before being washed $5 \times$ with $0.05 \%$ PBST. Secondary anti-mouse lgG1 (Santa Cruz sc-2005) was diluted into $1 \%$ milk in PBST at 1:10,000 and $50 \mu \mathrm{L}$ were added to each sample for $1 \mathrm{~h}$ at RT. Plates were developed with TMB substrate was added $(50 \mu \mathrm{L})$. The reaction was stopped with $50 \mu \mathrm{L}$ of $2 \mathrm{~N} \mathrm{H}_{2} \mathrm{SO}_{4}$. Plates were read using a SpectraMax M2 plate reader at 450 and $570 \mathrm{~nm}$ (Molecular Devices).

Enzymatic removal of Fc N-linked glycans using PNGase $\mathrm{F}$ Fc-glycans were removed from anti-LPS IgG following the manufacturer's standard protocol for PNGase F (Sigma P7367). Briefly, antibody solutions for deglycosylation were prepared by buffer exchanging $200 \mu \mathrm{g}$ of IgG1 anti-LPS (Virostat 6331) into $20 \mathrm{mM}$ ammonium carbonate. Denaturing solution was added and the sample was heated to $100^{\circ} \mathrm{C}$ for $10 \mathrm{~min}$. After cooling, $20 \mu \mathrm{L}$ of Triton X-100 (Sigma 93443) was added, and the sample was gently mixed. Prepared PNGase $F$ was added to the reaction mixture and incubated at $37^{\circ} \mathrm{C}$ for $1-3 \mathrm{~h}$. The reaction was stopped by heating the sample to $100^{\circ} \mathrm{C}$ for $5 \mathrm{~min}$, and then placed on ice to stop further enzymatic digestion. Samples were then buffer exchanged into sterile PBS using a $50 \mathrm{~K}$ MWCO filter (Millipore-Sigma UFC505008). Flow through was analyzed by sodium dodecyl sulfate-polyacrylamide gel electrophoresis (SDS-PAGE). Antibody concentration was measured using a NanoDrop One instrument (Thermo Scientific). Then, samples were stored at $4{ }^{\circ} \mathrm{C}$ until use.

SDS-PAGE and Western lectin blot to validate Fc N-glycan removal Protein samples $(5 \mu \mathrm{g})$ were prepared for SDS-PAGE by diluting in ultrapure water and mixing with $4 \times$ protein sample buffer (Invitrogen NP0007) and $1 \mu \mathrm{L}$ dithithreitol (Sigma 43816). Samples were heated at $70^{\circ} \mathrm{C}$ for $10 \mathrm{~min}$ and resolved by SDS-PAGE. Native anti-LPS IgG1 and human intravenous Ig (Privigen NDC 442-6-43710) were included as positive glycosylation controls. Two gels were run simultaneously for silver stain (Pierce Silverstain Kit, Thermo Scientific, 24612) and lectin blotting. Proteins were transferred from the gel to a nitrocellulose membrane using a Novex Semi-Dry blotting apparatus at $20 \mathrm{~V}$ for $45 \mathrm{~min}$ (Thermo Scientific SD1000). The membrane was rinsed several times with 
$0.1 \%$ PBST and blocked with $1 \times$ Carbo-Free $^{\mathrm{TM}}$ Blocking Solution (Vector Labs SP-5040) and for $1 \mathrm{~h}$ at RT. Biotinylated, mannosespecific ConA lectin was added to the membrane at a concentration of $2 \mu \mathrm{g} / \mathrm{mL}$ in PBS and incubated overnight at $4{ }^{\circ} \mathrm{C}$ with rocking (Vector Labs B-1005). After washing, anti-biotin horse radish peroxidase (Vector Labs SP3010) was added to the membrane at a 1:10,000 dilution in 0.1\% PBST for $1 \mathrm{~h}$ at RT. BioRad ECL reagent (Bio-Rad 107060) was used to develop the blot according to the manufacturer's instructions.

Transwell assay to evaluate Salmonella penetration across mucus Mouse GIM was collected as described above; $160-200 \mu \mathrm{L}$ of GIM was collected from each mouse. Salmonella was cultured to motility as described. A wiretrol applicator was used to transfer $40 \mu \mathrm{L}$ of mucus per sample were transferred to a 96-well, polycarbonate membrane transwell plate with $8 \mu \mathrm{M}$ pore size (Corning 3374). Next, $150 \mu \mathrm{L}$ of kanamycin-containing LB $(50 \mu \mathrm{g} /$ $\mathrm{mL}$ ) was pipetted into the bottom transwell compartment. Abs were prepared at $50 \mu \mathrm{g} / \mathrm{mL}$ to account for a 10-fold dilution. Five microliters of Abs were added to each sample, followed by $5 \mu \mathrm{L}$ of bacteria, and then mixed gently. Where antibody was not added, $5 \mu \mathrm{L}$ of buffer was added instead. Where bacteria were not added, $10 \mu \mathrm{L}$ LB was added to maintain the similar dilutions across samples. Transwell plates were incubated at $37^{\circ} \mathrm{C}$ for $4 \mathrm{~h}$ in the absence of $\mathrm{CO}_{2}$. Bacterial growth and transit from the mucuscontaining transwell to the receiver plate was followed over time by measuring $\mathrm{OD}_{600}$ at 30 min intervals using a SpectraMax $\mathrm{M} 2$ plate reader (Molecular Devices).

Mouse IgG1 Fab preparation and purification

Mouse IgG1 Fab was prepared from IgG1 anti-LPS (Virostat 6331) using the Pierce Mouse IgG1 Fab and $F\left(a b^{\prime}\right) 2$ Preparation Kit according to the manufacturer's instructions (Thermo Scientific 44980). Briefly, ficin resin was equilibrated and $150 \mu \mathrm{g}$ of $\operatorname{lgG} 1$ antiLPS were prepared using a Zeba Spin desalting column. The prepared IgG sample $(500 \mu \mathrm{L})$ was added to the immobilized ficin column. Digestion proceeded for $4 \mathrm{~h}$ in an end-over-end mixer at $37^{\circ} \mathrm{C}$. Next, the spin column was centrifuged to separate digest from immobilized ficin resin. Resin was washed three times with $0.5 \mathrm{~mL}$ of Protein A binding buffer. Wash and digest fractions were combined to yield a total volume of $2 \mathrm{~mL}$. After equilibration of the Nab Protein A column, digested $A b$ was added to the column. Protein A resin and sample were incubated at RT for 10 min with end-over-end mixing, before centrifugation to collect Fab fragments. Protein concentration was estimated by measuring the absorbance at $280 \mathrm{~nm}$ on a nanodrop.

Bacterial growth assay

Kanamycin-resistant Salmonella Typhimurium was cultured to an optical density of 0.6 (late-log phase) as described above. The bacterial culture was then diluted 1:20 into fresh LB media containing $50 \mu \mathrm{g} / \mathrm{mL}$ kanamycin and $20 \mu \mathrm{L}$ per well dispensed into different tubes containing varying concentrations of anti-LPS native, anti-LPS Fab, or non-specific Ab control in LB media. After thorough mixing, bacterial samples (total volume $200 \mu \mathrm{L}$ ) were dispensed into a sterile 96-well plate (Costar 3599) with three to five replicates per $\mathrm{Ab}$ concentration. Plates were placed at $37^{\circ} \mathrm{C}$ without $\mathrm{CO}_{2}$. Bacterial growth was monitored spectrophotometrically using SpectraMax M2 microplate reader at a wavelength of $600 \mathrm{~nm}$, with readings taken every $30 \mathrm{~min}$ over $4 \mathrm{~h}$. Since the molecular weight (MW) of the Ab Fab region is $\sim 50 \mathrm{kDa}$, or onethird the MW of a full-length $A b$, total protein concentration was decreased by one-third to maintain the same molar ratio of Fab binding sites using Fab alone vs. full-length $A b$.

Statistical analysis

Results were analyzed with one- or two-way ANOVA (analysis of variance) with Tukey's or Sidak's post test, respectively. Statistical tests were performed using, as appropriate, Student's paired $t$ test with the Prism (GraphPad) software. Differences between groups were considered significant at $p<0.05$. All error bars represent SD.

\section{ACKNOWLEDGEMENTS}

This work was supported by National Institutes of Health (http://www.nih.gov/) Grants R21A1093242 (S.K.L.), U19A1096398 (S.K.L.), and The David and Lucile Packard Foundation (https://www.packard.org/) 2013-39274 (S.K.L.), the Eshelman Institute of Innovation (http://unceii.org/, S.K.L.), and startup funds from the University of North Carolina Eshelman School of Pharmacy (https://pharmacy.unc.edu/; S.K.L.). The funders had no role in study design, data collection and analysis, decision to publish, or manuscript preparation.

\section{AUTHOR CONTRIBUTIONS}

S.K.L., B.S., and H.A.S. conceptualized and designed the experiments; H.A.S. performed experiments; H.A.S., J.N., and A.S. performed data analysis; A.T., M.G.F., and E.M. provided technical support and reagents; H.A.S. and S.K.L. wrote the paper; H.A.S. and S.K.L. edited the paper.

\section{ADDITIONAL INFORMATION}

The online version of this article (https://doi.org/10.1038/s41385-020-0267-9) contains supplementary material, which is available to authorized users.

Competing interests: Intellectual property associated with harnessing antibodymucin interactions described, in part, in this publication was developed at the University of North Carolina-Chapel Hill (UNC-CH), and has been licensed to Mucommune, LLC. S.K.L. is a founder of Mucommune and currently serves as its interim CEO, board of director, and scientific advisory board. S.K.L. owns company stock; S.K.L.'s relationship with Mucommune is subject to certain restrictions under University policy. The terms of this arrangement are being managed by UNC-CH in accordance with its conflict of interest policies.

Publisher's note Springer Nature remains neutral with regard to jurisdictional claims in published maps and institutional affiliations.

\section{REFERENCES}

1. Bergstrom, K. S. B. et al. Muc2 protects against lethal infectious colitis by disassociating pathogenic and commensal bacteria from the colonic mucosa. PLoS Pathog. 6, e1000902 (2010).

2. Que, F., Wu, S. \& Huang, R. Salmonella pathogenicity Island 1(SPI-1) at work. Curr. Microbiol. 66, 582-587 (2013).

3. Pelaseyed, T. et al. The mucus and mucins of the goblet cells and enterocytes provide the first defense line of the gastrointestinal tract and interact with the immune system. Immunol. Rev. 260, 8-20 (2014).

4. LaRock, D. L., Chaudhary, A. \& Miller, S. I. Salmonellae interactions with host processes. Nat. Rev. Microbiol. 13, 191-205 (2015).

5. Cornick, S., Tawiah, A. \& Chadee, K. Roles and regulation of the mucus barrier in the gut. Tissue Barriers 3, 1-2 (2015).

6. Sicard, J.-F., Le Bihan, G., Vogeleer, P., Jacques, M. \& Harel, J. Interactions of intestinal bacteria with components of the intestinal mucus. Front. Cell Infect. Microbiol. 7, 387 (2017).

7. Zarepour, M. et al. The mucin muc2 limits pathogen burdens and epithelial barrier dysfunction during Salmonella enterica serovar typhimurium colitis. Infect. Immun. 81, 3672-3683 (2013).

8. Rossez, Y., Wolfson, E. B., Holmes, A., Gally, D. L. \& Holden, N. J. Bacterial flagella: twist and stick, or dodge across the kingdoms. PLoS Pathog. 11, 1-15 (2015).

9. Hansson, G. C. Role of mucus layers in gut infection and inflammation. Curr. Opin. Microbiol. 15, 57-62 (2012).

10. Safaeian, M., Kemp, T., Rodriguez, C. A., Hildesheim, A. \& Falk, R. T. Determinants and correlation of systemic and cervical concentrations of total $\lg A$ and $\operatorname{lgG}$. Cancer Epidemiol. Biomark. Prev. 18, 2672-2676 (2009).

11. Mathias, A. et al. Role of secretory $\lg A$ in the mucosal sensing of commensal bacteria. Gut Microbes 0976, 688-695 (2014).

12. Daniele, R. P. Immunoglobulin secretion in the airways. Annu. Rev. Physiol. 52, 177-195 (1990).

13. Usala, S. J., Usala, F. O., Haciski, R., Holt, J. A. \& Schumacher, G. IgG and IgA content of vaginal fluid during the menstrual cycle. J. Reprod. Med. 34, 292-294 (1989). 
14. Olmsted, S. S. et al. Diffusion of macromolecules and virus-like particles in human cervical mucus. Biophys. J. 81, 1930-1937 (2001).

15. Saltzman, W. M., Radomsky, M. L., Whaley, K. J. \& Cone, R. A. Antibody diffusion in human cervical mucus. Biophys. J. 66, 508-515 (1994).

16. Wessler, T. et al. Using computational modeling to optimize the design of antibodies that trap viruses in mucus. ACS Infect. Dis. 2, 82-92 (2016).

17. Yang, B. et al. ZMappTM reinforces the airway mucosal barrier against ebola virus. J. Infect. Dis. https://doi.org/10.1093/infdis/jiy230, 1-10 (2018).

18. Wang, Y.-Y. et al. IgG in cervicovaginal mucus traps HSV and prevents vaginal herpes infections. Mucosal Immunol. 7, 1036-1044 (2014).

19. Schroeder, H. A. et al. Herpes simplex virus-binding lgG traps HSV in human cervicovaginal mucus across the menstrual cycle and diverse vaginal microbial composition. Mucosal Immunol. https://doi.org/10.1038/s41385-018-0054-z (2018).

20. Henry, C. E. et al. Anti-PEG antibodies alter the mobility and biodistribution of densely PEGylated nanoparticles in mucus. Acta Biomater. 43, 61-70 (2016).

21. Perez-vilar, J. \& Hill, R. L. The structure and assembly of secreted mucins. Biochemistry https://doi.org/10.1074/jbc.274.45.31751, 31,751-31,754 (1999).

22. Ermund, A., Schutte, A., Johansson, M. E. V., Gustafsson, J. K. \& Hansson, G. C. Studies of mucus in mouse stomach, small intestine, and colon. I. Gastrointestinal mucus layers have different properties depending on location as well as over the Peyer's patches. AJP Gastrointest. Liver Physiol. 305, G341-G347 (2013).

23. Lai, S., Hanes, J., Wang, Y.-Y. \& Wirtz, D. Micro- and macrorheology of mucus. Adv. Drug Deliv. Rev. 61, 86-100 (2010).

24. Rogier, E. W., Frantz, A. L., Bruno, M. E. C. \& Kaetzel, C. S. Secretory IgA is concentrated in the outer layer of colonic mucus along with gut bacteria. Pathogns (Basel, Switz.) 3, 390-403 (2014).

25. Mombaerts, P., Johnson, R. S., Herrup, K., Tonegawa, S. \& Papaioannouo, V. E. RAG-I-deficient mice have no mature B and T lymphocytes. Cell 68, 869-877 (1992).

26. Stecher, B. et al. Motility allows S. Typhimurium to benefit from the mucosal defence. Cell Microbiol. 10, 1166-1180 (2008).

27. Liévin-Le Moal, V., Fayol-Messaoudi, D. \& Servin, A. L. Compound(s) secreted by Lactobacillus casei strain Shirota YIT9029 irreversibly and reversibly impair the swimming motility of Helicobacter pylori and Salmonella enterica serovar Typhimurium, respectively. Microbiology (U. Kingd.) 159, 1956-1971 (2013).

28. Pontier-Bres, R. et al. Modification of Salmonella typhimurium motility by the probiotic yeast strain Saccharomyces boulardii. PLoS ONE 7, e33796 (2012)

29. Dempster, A., Laird, N. \& Rubin, D. Maximum likelihood from incomplete data via the EM algorithm. J. R. Stat. Soc. 39, 1-38 (1977).

30. Das, R., Cairo, C. W. \& Coombs, D. A hidden Markov model for single particle tracks quantifies dynamic interactions between LFA-1 and the actin cytoskeleton. PLoS Comput. Biol. 5, e1000556 (2009).

31. Abraham, L. et al. Limitations of Qdot labelling compared to directly-conjugated probes for single particle tracking of B cell receptor mobility. Sci. Rep. 7, 1-13 (2017).

32. Johnson, S., Meent, J. WVan De ., Phillips, R., Wiggins, C. H. \& Lindén, M. Multiple Lacl-mediated loops revealed by Bayesian statistics and tethered particle motion. Nucleic Acids Res. 42, 10265-10277 (2014).

33. Newby, J. M. et al. Technological strategies to estimate and control diffusive passage times through the mucus barrier in mucosal drug delivery. Adv. Drug Deliv. Rev. 124, 64-81 (2017).

34. Newby, J. M., Schaefer, A. M., Lee, P. T., Forest, M. G. \& Lai, S. K. Convolutional neural networks automate detection for tracking of submicron-scale particles in 2D and 3D. Proc. Natl. Acad. Sci. U.S.A. 115, 9026-9031 (2018).

35. Forbes, S. J., Eschmann, M. \& Mantis, N. J. Inhibition of Salmonella enterica serovar typhimurium motility and entry into epithelial cells by a protective antilipopolysaccharide monoclonal immunoglobulin a antibody. Infect. Immun. 76, 4137-4144 (2008)

36. Maurer, M. A. et al. Glycosylation of human IgA directly inhibits influenza A and other sialic-acid-binding viruses article glycosylation of human IgA directly inhibits influenza A and other sialic-acid-binding viruses. Cell Rep. 23, 90-99 (2018).

37. Pasetti, F., Simon, J., Sztein, M. \& Levine, M. Immunology of gut mucosal vaccines. Immunol. Rev. 239, 125-148 (2011).

38. Kamada, N. et al. Humoral immunity in the gut selectively targets phenotypically virulent attaching-and-effacing bacteria for intraluminal elimination. Cell Host Microbe 17, 617-627 (2015).

39. $\mathrm{Xu}$, J. et al. Mannose-binding lectin inhibits the motility of pathogenic salmonella by affecting the driving forces of motility and the chemotactic response. PLoS ONE 11, 1-14 (2016).

40. Michetti, P., Mahan, M. J., Slauch, J. M., Mekalanos, J. J. \& Neutra, M. R. Monoclonal secretory immunoglobulin-a protects mice against oral challenge with the invasive pathogen Salmonella-Typhimurium. Infect. Immun. 60, 1786-1792 (1992).

41. Davitt, C. J. H. \& Lavelle, E. C. Delivery strategies to enhance oral vaccination against enteric infections. Adv. Drug Deliv. Rev. 91, 52-69 (2015).

42. Minamino, T., Imae, Y., Oosawa, F. \& Kobayashi, Y. Effect of intracellular pH on rotational speed of bacterial flagellar motors. J. Bacteriol. 185, 1190-1194 (2003).

43. Wang, Y. Y. et al. Diffusion of immunoglobulin $g$ in shed vaginal epithelial cells and in cell-free regions of human cervicovaginal mucus. PLoS One 11, e0158338 (2016).

44. Lee, J., Kang, H. \& Woo, H. Stability of orally administered immunoglobulin in the gastrointestinal tract. J. Immunol. Methods 384, 143-147 (2012).

45. Yadav, V., Varum, F., Bravo, R., Furrer, E. \& Basit, A. W. Gastrointestinal stability of therapeutic anti-TNF antibodies a lgG1 monoclonal. Int. J. Pharm. 502, 181-187 (2016).

46. Carrillo-Conde, B., Brewer, E., Lowman, A. \& Peppas, N. Complexation hydrogels as oral delivery vehicles of therapeutic antibodies: an in vitro and ex vivo evaluation of antibody stability and bioactivity. Ind. Eng. Chem. Res. 54, 10197-10205 (2015).

47. Jasion, V. S. \& Burnett, B. P. Survival and digestibility of orally-administered immunoglobulin preparations containing lgG through the gastrointestinal tract in humans. Nutr. J. 14, https://doi.org/10.1186/s12937-015-0010-7 (2015).

48. Levinson, K. J., Jesus, M. De \& Mantis, N. J. Rapid effects of a protective Opolysaccharide-specific monoclonal IgA on Vibrio cholerae agglutination, motility, and surface. Infect. Immun. 83, 1674-1683 (2015).

49. Irani, V. et al. Molecular properties of human $\{\operatorname{lgG}\}$ subclasses and their implications for designing therapeutic monoclonal antibodies against infectious diseases. Mol. Immunol. 67, 171-182 (2015).

50. Juarez, P., Virdi, V., Depicker, A. \& Orzaez, D. Biomanufacturing of protective antibodies and other therapeutics in edible plant tissues for oral applications. Plant Biotechnol. J. 14, 1791-1799 (2016).

51. MacLennan, C. A., Martin, L. B. \& Micoli, F. Vaccines against invasive Salmonella disease: current status and future directions. Hum. Vaccin. Immunother. 10, 1478-1493 (2014).

52. Vela Ramirez, J. E., Sharpe, L. A. \& Peppas, N. A. Current state and challenges in developing oral vaccines. Adv. Drug Deliv. Rev. 114, 116-131 (2017).

53. Ensign, L. M. et al. Ex vivo characterization of particle transport in mucus secretions coating freshly excised mucosal tissues. Mol. Pharm. 10, 2176-2182 (2014).

54. Wang, Y. et al. The microstructure and bulk rheology of human cervicovaginal mucus are remarkably resistant to changes in $\mathrm{pH}$ Ying-Ying. Biomacromolecules 14, 4429-4435 (2014). 